\title{
Testing of Briquettes Made from Witbank Coal Fines with Polyvinyl Alcohol as Binder
}

\author{
C.N. Henning, N.T. Leokaoke, J.R. Bunt and F.B. Waanders.
}

\begin{abstract}
Approximately 12\% of South Africa's mined coal can be classified as fine coal. Fine coal is primarily formed through mechanical mining methods and can cause blockage in equipment, transportation mechanisms and silos. Agglomeration methods are therefore used to simplify the handling of coal fines as well as enable the use of the fines in industrial processes. This report focuses on the briquetting of coal fines from the Witbank area. Polyvinyl alcohol (PVA) was used as the binder and mechanical strength tests, i.e. compressive strength, impact resistance, abrasion resistance and water resistance, were used to determine the effectiveness of the binder. Thermogravimetric analysis (TGA) was used to determine the reactivity of the briquettes and the estimated cost of the briquettes was compared to binderless briquettes to determine the financial feasibility of the binder. The optimal briquette was determined to have a formulation (PVA vs. water) of $5 \%$ and a dosage (binder vs. coal) of $0.9 \%$ with a $7 \%$ increase in compressive strength and a $3 \%$ increase in price. The calorific value, $20.7 \mathrm{MK} / \mathrm{kg}$, and the ash content, $26 \%$, of the coal was not impacted by the PVA in the binder. However, neither the paraffin nor the spray increased the water resistance of the briquettes and other waterproofing methods should be investigated.
\end{abstract}

Index Terms - Agglomeration, Coal fines, Polyvinyl alcohol, Thermogravimetric analysis

\section{INTRODUCTION}

\section{A. Coal fines in South Africa}

Roughly $6 \%$ of the world's coal reserves are in South Africa [1] with around $80 \%$ of the reserves situated in the central basin, i.e. Witbank, Highveld and Ermelo [2], [3]. Mechanical mining methods have increased the amount of coal fines that are dumped in slurry ponds, discard dumps or fine coal stockpiles [4] with approximately $12 \%$ of the yearly run-of-mine (ROM) tonnage classified as fines [3].

The agglomeration of coal fines involves methods that bind the fines into a mass that has similar characteristics to the parent coal [5] which can make the coal fines useable while also decreasing the amount of pollution to the environment due to

This work was supported by the North West University, Potchefstroom campus.

C. N. Henning is a student at the School of Chemical and Minerals Engineering, North West University, Potchefstroom, South Africa.

N. T. Leokaoke is a lecturer at the North West University, Potchefstroom, South Africa .

J. R. Bunt is a lecturer at the North West University, Potchefstroom, South Africa.

F. B. Waanders is a lecturer at the North West University, Potchefstroom, South Africa. dumping.

\section{B. Agglomeration}

According to England [5] there are three traditional methods to agglomerate coal fines: briquetting, pelletizing and spherical agglomeration.

The first step in the briquetting process is ensuring that the moisture content of the screened coal fines is acceptable by either drying the fines if they are too wet or adding water if they are too dry [6]. The optimum moisture content of Witbank coal fines is $3.6 \%-5.9 \%$ [7]. The fines are then mixed with a binder and fed to a briquetting machine where the mixture it pressed through a roller die. Lastly, the briquettes are cured and packaged before being transported.

\section{Binders}

Binders can be used to enhance the bonding properties of briquettes however, a suitable binder needs to create a strong, waterproof briquette that does not hinder the use of the coal or diminish the coal quality, is environmentally safe and economically feasible [8], [6]. Binders can be classified as inorganic and organic [8]. Inorganic binders include clay, lime, cement and water glass whereas organic binders include wood products, sugar-factory residues, starch, tars and pitches from coal, natural asphalts and petroleum products.

The price of binders is an important variable to consider because the price of the briquettes should be able to compete with the price of ROM coal. A compromise between the increase in mechanical strength and the increase in price due to binder addition should therefore be reached.

Polyvinyl alcohol is the main component in wood glue and has also been used as a binder in previous studies contributing to an increase in mechanical strength, but not the water resistance of the briquettes [9], [10]. Table I gives an estimate of the price of coal and PVA [9] that can be used to determine the price increase caused by the different amounts of binder addition during manufacturing.

TABLE I: PRICE OF COAL AND POLYVINYL ALCOHOL

\begin{tabular}{lcc}
\hline \hline \multirow{2}{*}{ Range } & \multicolumn{2}{c}{ Price (R/ton) } \\
& Coal & PVA \\
\hline Minimum & 150 & 20000 \\
Maximum & 400 & 28000 \\
Average & 275 & 24000 \\
\hline \hline
\end{tabular}




\section{Gasification}

Coal is converted into synthesis gas in the presence of a gasifying agent during gasification [11]. There are two steps in the process, namely pyrolysis during which char is formed and the gasification of the formed char [12]. Carbon dioxide can be used as a gasifying agent [13].

\section{METHOD}

Briquettes were manufactured using a Komarek briquetting machine with coal fines from the Witbank area and polyvinyl alcohol (PVA) as binder.

The briquettes were tested over a period of 21 days and compared to binderless briquettes to determine the optimal briquette combination. The mechanical tests that were used are: compressive strength test, drop shatter test, tumbler test and water resistance test.

Two methods were used to create a hydrophobic layer around the briquettes to increase the water resistance. The first method consisted of a combination of a household multi-surface cleaning spray and a clear lacquer spray and the second was a paraffin dip.

\section{A. Compressive strength test}

The compressive strength (CS) of a briquette is the maximum load that the briquette can withstand before cracking. This was determined by placing a single briquette at a time on a tensile strength testing machine and manually lowering a plate onto the briquette until it cracked. The fracture load can be compared to that of other briquettes with different dimensions by using (1).

$$
\operatorname{CS}(\mathrm{kPa})=\frac{\text { Fracture load }(\mathrm{N})}{\text { Area of fracture }\left(\mathrm{m}^{2}\right)}
$$

The minimum compressive strength according to Richards is $350 \mathrm{kPa}[14]$.

\section{B. Drop shatter test}

The drop shatter test is used to determine the impact resistance and friability, i.e. durability, of briquettes. During the test a single briquette was dropped from a height of $1.86 \mathrm{~m}$ until the briquette shattered, at which point the number of drops, the number of pieces the briquette broke into and the weight of the largest piece was recorded.

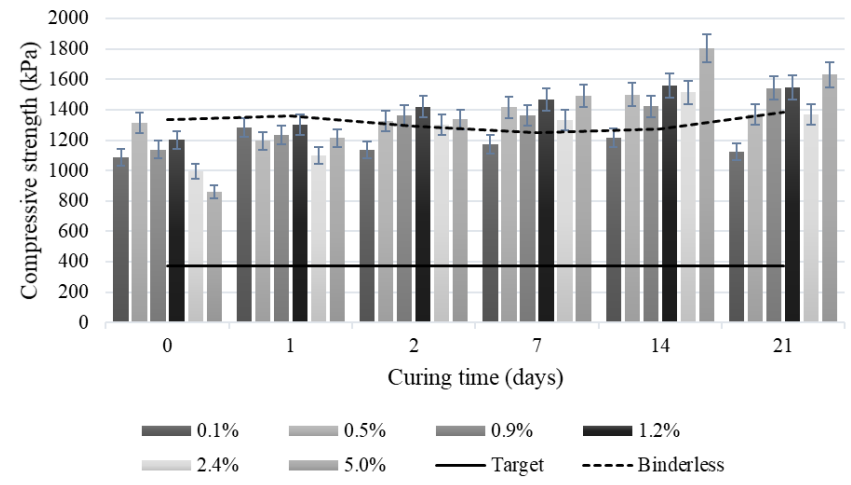

Fig. 1. Compressive strength of various binder dosages.

The impact resistance (IRI) index and friability index (FR) were then calculated with (2) and (3) respectively.

$$
\begin{aligned}
& I R I=\frac{\text { number of drops }}{\text { number of pieces }} \times 100 \\
& F R=\frac{\text { weight of largest piece }}{\text { weight of briquette }} \times 100
\end{aligned}
$$

The minimum requirement for a viable briquette is an IRI value of 50 [14] and an FR value of $80 \%$ [15].

\section{Tumbler test}

The transportation and handling of briquettes can cause them to rub against each other and the container walls which is why abrasion resistance, a durability measurement, should be quantified. A small-scale form of the Richards tumbler test [14] was used to test the abrasion resistance of the briquettes. A sample of approximately $17 \mathrm{~g}$ was rotated in a tube $(70 \mathrm{~mm}$ length and $51 \mathrm{~mm}$ internal diameter) at $80 \mathrm{rpm}$ for 197 revolutions. The sample was then screened on a $7.6 \mathrm{~mm}$ mesh screen and the oversize was weighed to determine the percentage fines that were produced. The maximum amount of fine coal is $5 \%$ [14].

\section{Water resistance test}

Briquettes should be water resistant to avoid disintegration or loss of material when exposed to wet conditions. An immersion-in-water test was used to determine the water resistance of the briquettes where a single briquette was weighed and immersed in water for a period of 30 minutes. Light pressure was applied at 10-minute intervals to check for disintegration. If no breakdown was observed the briquette was wiped dry and weighed again to calculate the water resistance index (WRI) with (4).

$$
W R I=100-\% \text { water absorbed }
$$

The WRI should be above 95\% [11].

\section{E. Optimization}

The PVA versus water ratio, i.e. formulation of the binder, was tested by using a binder versus coal fines ratio, i.e. dosage, of $1.2 \%$. The optimal formulation based on mechanical tests, price due to PVA addition and handleability (HD) of the binder was then further tested to determine the optimal dosage. Equation (5) shows the weights that were assigned to the variables in the formulation tests.

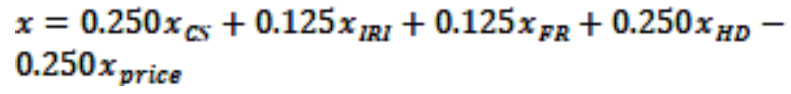

In (5) the $x$ values represent the fractional increase of the different formulations compared to the binderless briquette. The formulations that were considered are: $5.00 \%, 7.50 \%, 10.0 \%$, $12.5 \%, 15.0 \%, 17.5 \%, 20.0 \%$.

Equation (6) was used to calculate the optimal dosage from the following dosages: $0.1 \%, 0.5 \%, 0.9 \%, 1.2 \%, 2.4 \%, 5.0 \%$. $x=0.3333 x_{C S}+0.1665 x_{I R I}+0.1665 x_{F R}-0.3333 x_{\text {price }}$ 
In (6) the $x$ values represent the fractional increase of the different dosages compared to the binderless briquette.

\section{F. Reactivity test}

The optimal and binderless briquettes were both charred and analyzed in a thermogravimetric analysis (TGA) oven to determine the effect of the binder on the reactivity of the briquettes. During the initial phase of the analysis the briquette was exposed to $\mathrm{N}_{2}$ gas and heated non-isothermally to $105^{\circ} \mathrm{C}$ at a rate of $5{ }^{\circ} \mathrm{C}$, were the temperature was held constant for 20 min to remove the moisture in the briquettes. The temperature was then increased at a rate of $10^{\circ} \mathrm{C} / \mathrm{min}$ to $1000{ }^{\circ} \mathrm{C}$. This is the pyrolysis step of the analysis. When no further mass loss was observed the gas was switched to $\mathrm{CO}_{2}$ to analyze the gasification process under isothermal conditions.

The calorific value $(\mathrm{CV})$ of the optimal and binderless briquettes was also tested using a bomb calorimeter to determine the impact of the binder on the heating value of the coal.

\section{RESULTS AND DISCUSSION}

\section{A. Compressive strength}

The compressive strength of the briquettes increased with the increase of PVA that was present in the binder, but with an error bar of 5\% the values were very close together, as seen in Fig. 1. The compressive strength of all the briquettes was also well above the minimum value of $350 \mathrm{kPa}$ [14] however, none of the briquettes reached the compressive strength of the ROM coal sample which was calculated as 4.2 $\mathrm{MPa}$.

\section{B. Impact resistance and durability}

The difference in impact resistance and friability of the briquettes compared to a binderless briquette, shown in Table II and Table III, did not follow a clear pattern. However, the friability of the briquettes appears to decrease with the addition of PVA, except in small dosages such as $0.1 \%$ and $0.5 \%$. The impact resistance of the briquettes however increased when PVA was added, but the magnitude of the increase does not correlate with the amount of PVA that was added.

The abrasion resistance was satisfactory for all the briquettes

TABLE II: OPTIMIZATION OF THE BINDER FORMULATION

\begin{tabular}{|l|l|l|l|l|l|l|}
\hline Formulation & CS & IRI & FR & Price & HD & $\mathrm{x}$ \\
\hline $5.0 \%$ & 0.043 & 0.375 & -0.129 & 0.040 & 1.00 & 0.281 \\
\hline $7.5 \%$ & 0.060 & 0.252 & -0.053 & 0.067 & 1.00 & 0.273 \\
\hline $10.0 \%$ & 0.122 & 0.157 & -0.169 & 0.093 & 1.00 & 0.256 \\
\hline $12.5 \%$ & 0.184 & 0.108 & -0.158 & 0.119 & 0.50 & 0.135 \\
\hline $15.0 \%$ & 0.276 & 0.197 & -0.050 & 0.145 & 0.50 & 0.176 \\
\hline $17.5 \%$ & 0.379 & 0.354 & -0.043 & 0.171 & 0.20 & 0.141 \\
\hline $20.0 \%$ & 0.418 & 0.350 & -0.353 & 0.197 & 0.20 & 0.105 \\
\hline
\end{tabular}

and consequently, all the binder concentrations were considered during optimization. The values were however very close in scope, with less than $1 \%$ difference, and the abrasion resistance values were therefore not used in the optimization calculations.
TABLE III: OPTIMIZATION OF THE BINDER DOSAGE

\begin{tabular}{|l|l|l|l|l|l|}
\hline Dosage & CS & IRI & FR & Price & $\mathrm{x}$ \\
\hline $0.1 \%$ & -0.157 & 0.265 & 0.096 & 0.003 & 0.007 \\
\hline $0.5 \%$ & 0.035 & 0.149 & 0.055 & 0.017 & 0.040 \\
\hline $0.9 \%$ & 0.068 & 0.505 & -0.033 & 0.030 & 0.091 \\
\hline $1.2 \%$ & 0.120 & 0.221 & -0.191 & 0.040 & 0.032 \\
\hline $2.4 \%$ & 0.040 & 0.019 & -0.013 & 0.081 & -0.013 \\
\hline $5.0 \%$ & 0.239 & 0.060 & -0.149 & 0.168 & 0.009 \\
\hline
\end{tabular}

\section{Water resistance}

None of the briquettes with only binder added were water resistant. The waterproofing methods were subsequently tested on the briquettes. The first waterproofing method caused the outside layer of the briquette to separate from the briquette while the rest of the briquette completely disintegrated. The briquettes that were dipped in paraffin were partially water resistant on the day the briquettes were waterproofed, but the water-resistance decreased with curing time. This could be due to the paraffin evaporating off the briquettes. The two methods are therefore not acceptable options.

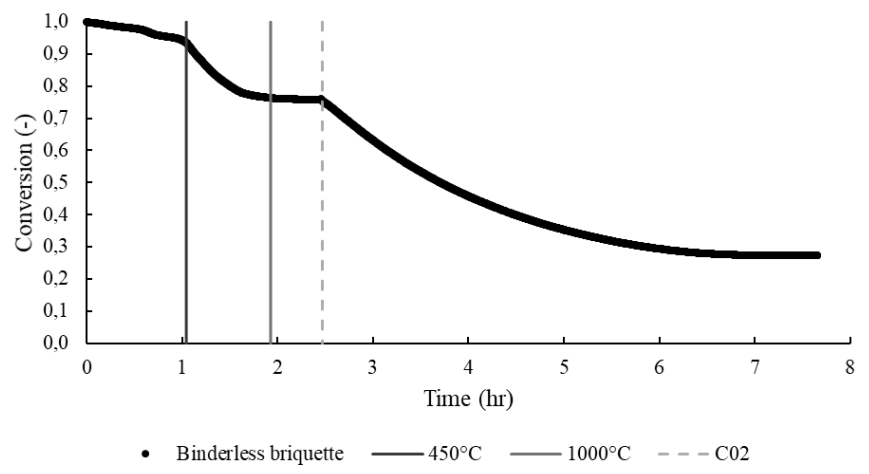

Fig. 2. TGA curve of the binderless briquette.

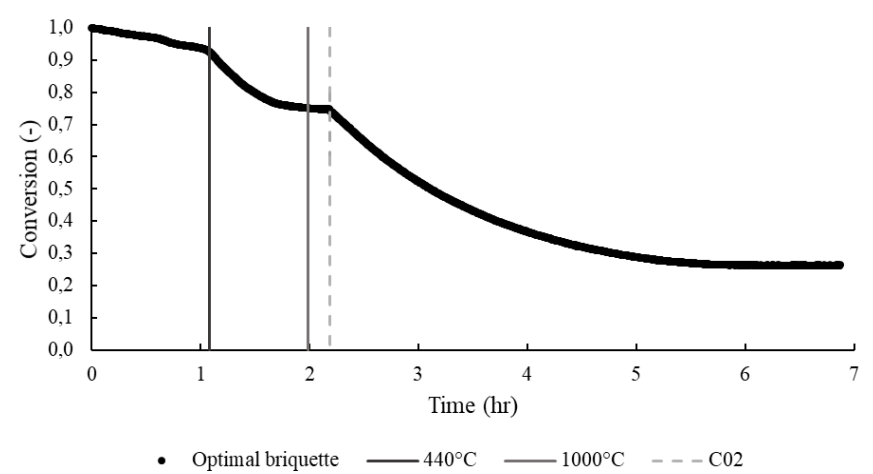

Fig. 3. TGA curve of the optimal briquette.

TABLE IV: TGA PHASE COMPARISON

\begin{tabular}{|l|l|l|l|l|}
\hline \multirow{2}{*}{\multicolumn{1}{|c}{ Phase }} & \multicolumn{2}{c|}{ Binderless } & \multicolumn{2}{c|}{ Optimal } \\
\cline { 2 - 5 } & Fraction (-) & Time (h) & Fraction (-) & Time (h) \\
\hline Organic material & 0.07 & 1.0 & 0.08 & 1.1 \\
\hline Thermal fracturing & 0.17 & 0.9 & 0.17 & 0.9 \\
\hline Gasification & 0.49 & 4.3 & 0.49 & 3.6 \\
\hline Inorganic material & 0.27 & - & 0.26 & - \\
\hline
\end{tabular}




\section{A. Optimization}

The drop shatter test showed no clear trend and all the briquettes met the minimum requirement of the tumbler test. The compressive strength of the briquettes increased with an increase in PVA in the formulation, but due to the upsurge in price and difficult handleability of the higher concentrations the optimal formulation was calculated as $5.00 \%$, Table II.

The optimal binder formulation was then used to determine the optimal dosage of $0.90 \%$, shown is Table III. The price difference between the optimal briquette and binderless briquette is roughly $\mathrm{R} 8.30$ per ton.

\section{B. Reactivity}

The calorific value of the binderless and optimal briquettes was $20.7 \mathrm{MJ} / \mathrm{kg}$ and $20.6 \mathrm{MJ} / \mathrm{kg}$ respectively, which is consistent with the expected calorific value [16], $5.1 \mathrm{MJ} / \mathrm{kg}-$ 26.26 MJ/kg, of coal from the Witbank area. The binder therefore does not influence the heating value of the coal.

The mass versus time curve of the binderless briquette, Fig. 2, and the optimal briquette, Fig. 3, are compared in Table IV. The amount of organic, $7-8 \%$, and inorganic material, $26 \%-27 \%$, is the same which indicates that the PVA in the optimal briquette does not increase the ash content of the briquettes. This could be due to the rapid decomposition of PVA at temperatures above $200{ }^{\circ} \mathrm{C}$ or the small amount of PVA that is present in the briquettes.

The time that was necessary to remove the organic material was similar for the binderless and optimal briquettes and the temperature at which this occurred was $450{ }^{\circ} \mathrm{C}$ for the binderless briquette and $440{ }^{\circ} \mathrm{C}$ for the optimal briquette. The error for the temperature readings is $\pm 40{ }^{\circ} \mathrm{C}$ which shows that the temperatures for the two briquettes are comparable.

The time required during gasification however was different for the briquettes; the optimal briquette required $44 \mathrm{~min}$ less time than the binderless briquette to gasify. This could be due to the smaller amount of coal that was gasified after the binder was removed from the sample during the initial heating stages.

\section{CONCLUSIONS}

The optimal briquette dosage was calculated as $0.9 \%$ with a formulation of $5 \%$. The small price difference between the optimal briquette and binderless briquette shows that PVA is a viable binder option. The binder did not impact the heating value or the ash content of the coal which was $20 \mathrm{MJ} / \mathrm{kg}$ and $27 \%$ respectively. However, neither paraffin nor the spray increased the water resistance of the briquettes and other methods should therefore be investigated.

\section{ACKNOWLEDGMENT}

The authors gratefully acknowledge the support received from the North West University, Potchefstroom campus.

\section{REFERENCES}

[1] R. M. S. Falcon. (July 2013). Coal, coke and carbon in the metallurgical industry. Presented at the University of the Witwatersrand. [Online]. Available:

http://www.fossilfuel.co.za/conferences/2013/CoalCokeCarbon/Day-On e/01-Rosemary-Falcon.pdf
[2] R. M. S. Falcon, "Coal resources of South Africa and their unique qualities," presented at the Fossil Fuel Foundation's (FFF) independent power generation (IPP) one-day conference, Rosebank, Johannesburg, March 17, 2016.

[3] L. S. Jeffrey, "Characterization of the coal resources of South Africa," The South African Institute of Mining and Metallurgy, vol. 105, pp. 95-102, February 2005

[4] J. De Korte and L. S. Jeffrey, "South African coal quality for independent power producers," presented at the Fossil Fuel Foundation's (FFF) independent power generation (IPP) one-day conference, Rosebank, Johannesburg, March 17, 2016.

[5] T. England. (2000). The economic agglomeration of fine coal for industrial and commercial use: A review of past and present work both locally and internationally. [Online]. Available: http://www.coaltech.co.za/chamber\%20databases\%5Ccoaltech\%5CCo m_DocMan.nsf/0/09EFEE68D9257C164225781B00364F21/\$File/Task $\% 204.4 \% 201 \% 20 \% 20$ Agglomoration $\% 20$ of $\% 20$ Fine $\% 20$ Coal $\% 20-\% 2$ 0Trevor\%20England.pdf

[6] P. L. Waters, "Binders for fuel briquettes: a critical survey," in Division of Mineral Chemistry, Technical Communication, vol. 51, Ed. Canberra: CSIRO, 1969, pp. 44-69.

[7] S. J. Mangena, G. J. De Korte, R. I. McCrindle and D. L. Morgan, "The amenability of some Witbank bituminous ultrafine coals to binderless briquetting," Fuel Processing Technology, vol. 85, pp. 1647-1662, October 2004

https://doi.org/10.1016/j.fuproc.2003.12.011

[8] J. E. Mills, Binders for coal briquets, Washington, DC: Department of the Interior, 1908.

[9] P. Venter and N. Naude, "Evaluation of some optimum moisture and binder conditions for coal fines briquetting," The Journal of the Southern African Institute of Mining and Metallurgy, vol. 115, pp. 329-333, April 2015. https://doi.org/10.17159/2411-9717/2015/v115n4a9

[10] U. Habib, A. U. Khan and M. Habib, "Compressive strength and heating values evaluation of the indigeneous coal briquettes of Pakistan (KPK Province)," International Journal of Current Research, vol. 5, no. 7, pp. 124-131, June 2013.

[11] N. T. Modiri, "An evaluation of coal briquettes using various binders for application in fixed-bed gasification," M.Eng. dissertation, Dept. Chem. Eng., North West Univ., Potchefstroom, SA, 2016.

[12] L. Liu, Y. Cao and Q. Liu, "Kinetic studies and structure characteristics of coal cahr inder pressurized $\mathrm{CO}_{2}$ gasification conditions," Fuel, vol. 146, pp. 103-110, April 2015. https://doi.org/10.1016/j.fuel.2015.01.002

[13] H. H. Schobert, Chemistry of fossil fuels and biofuels, Cambridge: Cambridge University Press, 2013. https://doi.org/10.1017/CBO9780511844188

[14] S. R. Richards, "Physical testing of fuel briquettes," Fuel Processing Technology, vol. 25, pp. 89-100, June 1990. https://doi.org/10.1016/0378-3820(90)90098-D

[15] N. Kaliyan and R. V. Morey, "Factors affecting strength and durability of densified biomass products," Biomass and Bioenergy, vol. 33, pp. 337-359, March 2009. https://doi.org/10.1016/j.biombioe.2008.08.005

[16] P. J. Hancox and A. E. Goetz, "Douth Africa's coalfields - a 2014 perspective," International Journal of coal geology, vol. 132, pp. 170-254, October 2014 https://doi.org/10.1016/j.coal.2014.06.019

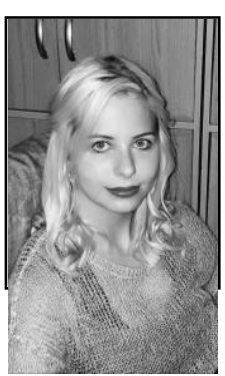

Chantalé N. Henning is a student at North West University, Potchefstroom, South Africa. She is currently studying towards a degree in chemical engineering and is set to graduate in 2018 . 